\title{
Two differentially active alternative promoters control the expression of the zebrafish orphan nuclear receptor gene Rev-erb $\alpha$
}

\section{Tomoko Kakizawa, Shin-ichi Nishio, Gerard Triqueneaux, Stephanie Bertrand, Juliette Rambaud and Vincent Laudet}

\author{
Laboratoire de Biologie Moléculaire de la Cellule, CNRS UMR 5161, INRA LA 1237, IFR 128 BioSciences Lyon-Gerland, Ecole Normale Supérieure de Lyon, 46 allée d'Italie, 69364 \\ Lyon cedex, France \\ (Requests for offprints should be addressed to V Laudet; Email: vincent.laudet@ens-lyon.fr) \\ T Kakizawa and S-i Nishio contributed equally to this work
}

\begin{abstract}
The orphan nuclear receptor Rev-erb $\alpha$ (NR1D1) plays an important role in the regulation of the circadian pacemaker and its expression has been shown to be regulated with a robust circadian rhythm in zebrafish and mammals. In addition, in zebrafish its expression has been shown to be developmentally regulated. In order to analyze the mechanisms of the $z f R e v$-erb $\alpha$ gene regulation, we have isolated its $5^{\prime}$-upstream region. We found that two promoters control the zfRev-erb $\alpha$ expression. The first one (ZfP1) is characterized by a very high degree of sequence identity with the mammalian $\mathrm{P} 1$ promoter and contains, as the mammalian P1, a functional Rev-erb $\alpha$-binding site (RevDR2). Inhibition of zfRev-erb $\alpha$ activity in zebrafish embryos using antisense-morpholino knockdown results in an increase of zfRev-erb $\alpha$ gene expression suggesting that zfRev-erb $\alpha$ is repressing its own transcription in vivo. In addition, we show that ROR orphan receptors also regulate in vitro and in vivo zfRev-erb $\alpha$ gene expression through the same RevDR2 element. In contrast, the second promoter ZfP2 is strikingly different from the mammalian P2: its sequence is not conserved between zebrafish and mammals and is not regulated by the same transcription factors. Together, these data suggest that ZfP1 is orthologous to the mammalian P1 promoter, whereas zebrafish ZfP2 has no mammalian ortholog and does not function like ZfP1 to control Rev-erb $\alpha$ expression.
\end{abstract}

Journal of Molecular Endocrinology (2007) 38, 555-568

\section{Introduction}

Rev-erb $\alpha$ belongs to the nuclear receptor (NR) superfamily, which includes receptors for steroids, thyroid hormones, retinoic acid, and vitamin $\mathrm{D}$, as well as orphan receptors. In mammals, Rev-erb $\alpha$ is encoded on the opposite strand of the thyroid hormone receptor $\alpha$ gene (Lazar et al. 1989, Miyajima et al. 1989). Rev-erbs form a group of orphan NRs, with three different genes: Rev-erb $\alpha$ (NR1D1; NRs Nomenclature Committee, 1999; also called ear-1), Rev-erb $\beta$ (NR1D2 also called RVR, ear1b, BD73, or HZF-2; Bonnelye et al. 1994, Dumas et al. 1994, Pena-de-Ortiz \& Jamieson 1997), and Rev-erby that has been lost specifically in mammals (Bertrand et al. 2004; SB). To date, no ligand has been identified for the Rev-erbs. Interestingly, their Drosophila homolog encoded by the E75 gene contains a heme molecule that can interact with nitric oxide and carbon monoxide suggesting that E75 could be a gas sensor (Reinking et al. 2005). It is not yet known if this feature is also conserved in mammalian Rev-erbs. The ligandbinding domain of Rev-erbs lacks the C-terminal
AF2-AD domain, which plays a role in activation, an observation in line with the notion that Rev-erbs act as transcriptional repressors. Rev-erb $\alpha$ has been shown to bind DNA as a monomer on a specific sequence called Rev-erb-response element (RevRE), which contains an AGGTCA motif (Harding \& Lazar (1993)) and also as a homodimer to RevDR2 elements composed of one classic RevRE followed by an AGGTCA motif separated by two nucleotides, most often CT (Harding \& Lazar 1995, Adelmant et al. 1996). In phylogenetic trees, Rev-erbs are related to the retinoic acid-related orphan receptor (ROR), consistent with the fact that these receptors share the same response element (BeckerAndre et al. 1993, Giguere et al. 1994, Laudet 1997). It has been reported that there is a crosstalk between Reverbs and RORs and that they regulate gene expression with opposed activities through RevRE elements (Forman et al. 1994, Retnakaran et al. 1994). Recently, this regulatory antagonism was also observed in the circadian pathway and it has been shown that Bmall is up- or down-regulated by ROR and Rev-erb respectively (Preitner et al. 2002, Triqueneaux et al. 2004, Akashi \& 
Takumi 2005, Guillaumond et al. 2005). Indeed, the promoters of human and rat Rev-erb $\alpha$ were isolated and it has been established that they are regulated by Reverb $\alpha$ and ROR with opposite activity through a RevDR2 element located close to the transcriptional start site (Adelmant et al. 1996, Raspe et al. 2002).

The biological function played by Rev-erb $\alpha$ has remained unclear, until it was observed that Rev-erb $\alpha$ expression is strongly circadian in most of the tissues in mammals and zebrafish (Balsalobre et al. 1998, Delaunay et al. 2000, Torra et al. 2000). Indeed, genetic and functional evidence suggests that Rev-erb $\alpha$ is a major player in the control of circadian clocks (reviewed in Emery \& Reppert 2004). In mammals, Rev-erb $\alpha$ directly regulates the major clock gene Bmal1, which acts on the positive limb of the pacemaker driving circadian clocks (Preitner et al. 2002). In addition, we and others have previously reported that the promoter of human Reverb $\alpha$ is activated by CLOCK-BMAL1 heterodimer and repressed by PER and CRY proteins (Preitner et al. 2002, Triqueneaux et al. 2004), suggesting that Rev-erb $\alpha$ expression is directly under the control of the circadian clock. All these data suggest that Rev-erb $\alpha$ is a primary determinant of the feedback loop that regulates Bmal1 transcription (Preitner et al. 2002, Emery \& Reppert 2004, Yin \& Lazar 2005).

In addition, it has been reported that the expression of Rev-erb $\alpha$ increases during adipogenesis and decreases during myogenesis. Therefore, a role of Rev-erb $\alpha$ has been proposed in myogenic differentiation or adipocyte differentiation (Chawla and Lazar 1993, Downes et al. 1995, Laitinen et al. 2005). In line with these findings, it has been shown that Rev-erb $\alpha$ controls the expression of numerous genes important for lipid homeostasis, such as ApoAl or ApoCIII (Vu-Dac et al. 1998, Gervois et al. 1999, Coste and Rodriguez 2002, Laitinen et al. 2005). Other evidence suggests that Rev-erb $\alpha$ is tightly regulated; in humans, it has been shown that the activity of its promoter is down-regulated by Rev-erb $\alpha$ itself through the RevDR2 element (Adelmant et al. 1996), although the in vivo significance of this regulation has never been rigorously tested. It has also been shown that in mammals, Rev-erb $\alpha$ is regulated by PPAR $\alpha$ through the RevDR2 site (Gervois et al. 1999, Canaple et al. 2006). During zebrafish embryogenesis, Rev-erb $\alpha$ expression has been observed to be both circadian and developmentally regulated. The expression was shown to start at 24-hours post-fertilization (hpf) specifically in the pineal gland, then the day after ( $48 \mathrm{hpf}$ ) in the pineal gland and retina and then, after 1 more day (72 hpf) in the pineal gland, retina, and optic tectum (Delaunay et al. 2000).

Given this striking expression pattern, we thought that the zebrafish would be useful to decipher the mechanisms by which this expression is tightly controlled. The zebrafish is an excellent model system for an in vivo promoter analysis, because of its transparency during embryonic development, and since it is possible to interfere with gene expression using morpholino (MO) injections (Nasevicius \& Ekker 2000). In this study, we isolate the $5^{\prime}$-region of the zebrafish Rev-erb $\alpha$ gene and we found that in zebrafish, as in mammals, Reverb $\alpha$ expression is controlled by two promoters, ZfP1 and ZfP2. These promoters drive expression of two Rev$\operatorname{erb} \alpha$ isoforms with similar repressive properties. We show that $\mathrm{ZfP} 1$ is conserved and functionally similar to the mammalian $\mathrm{P} 1$ promoter, whereas ZfP2 is divergent both in its genomic organization and function.

\section{Materials and methods}

\section{Plasmid constructions}

Full-length cDNA of zfRev-erb $\alpha$ (zfRev-erb $\alpha 1)$ and a version encoding a short isoform (zfRev-erb $\alpha 2$ ) were isolated by using reverse-transcription coupled to PCR (RT-PCR) from adult zebrafish total RNA. These cDNAs were subsequently subcloned into pCDNA3 and pCSII + vectors (Invitrogen). The primers used for PCR and cloning are indicated below. The position of each primer is indicated according to the numbering system of the sequence of the promoter region depicted in Fig. 1. zfRev-erb $\alpha 15^{\prime}$ primer: 5'-CATAATGACTTTACTGGGGCTC-3' ${ }^{\prime}$ (positions +257 to +274 ). zfReverb $\alpha 25^{\prime}$ primer: $5^{\prime}$-TCCATGTACAGTGAGAATTC-3' (positions +3717 to +3736 ). zfRev-erb $\alpha$ common $3^{\prime}$ primer: 5'-TCAGGCATCAATGCGGAAAGACAG-3 ${ }^{\prime}$ (reverse) positions 1979-2002 of the zfRev-erb $\alpha$ cDNA (Genbank accession number: AY391444).

To study the genomic $5^{\prime}$-region, a $14 \mathrm{~kb}$ genomic DNA fragment containing the entire zfRev-erb $\alpha$ coding region was isolated from a genomic DNA library in $\lambda$ FIX II (a generous gift of Christine and Bernard Thisse). A $6.5 \mathrm{~kb}$ fragment containing the $5^{\prime}$-regulatory region was subcloned, sequenced (Fig. 1), and further characterized (see Fig. 2A). It contains a $3079 \mathrm{bp}$ region upstream of exon 1, an intron 1 of $3350 \mathrm{bp}$, and a part of exon 2 (see Fig. 1 and Supplementary Fig. 2B). This sequence has been deposited in Genbank with the following accession number: AY336123. This large fragment, called zfRev-erb $\alpha$ full, was obtained by LA PCR (TaKaRa Shuzo, Kyoto, Japan) using the following pair of primers: Full $5^{\prime}$ primer: 5'-CCGCTCGAGCCTGCTGGCTGGATTATGGTACACCACTGCGCT-3' (sense; positions -2858 to -2827 ). Full $3^{\prime}$ primer: $5^{\prime}$-TCGGGATCCGATCCAATGTATGATATCACCCCACCTGGTGGT-3' (reverse; positions +3650 to +3683$)$. The amplified product was subcloned into XL-TOPO vector (Invitrogen).

The constructs containing the zfRev-erb $\alpha$ first (ZfP1) or second (ZfP2) promoters were obtained by PCR amplification using zfRev-erb $\alpha$ full as a template. The 
-2400 CTGGGCTGCC TCTCACGTGC AgTGTCACGC ACTGTTGTtA tACAGGTGAg AATGATtAat CATACCTGCT ATAAGGCGCC

-2320 CGAGTGCTTT CACGTGAGTG CAACAAGTGG CTCGTGCATC GCCATGTTCG GAATAAGTGA TGTACGGATG TGACTCTTG

Th 2320 CGATG

- 2240 TGCTGCGGG TGGTCTATTT TTTTAAGTAG CACGGTTTTG TTCACAGGCA CGTGTTTGAC GGAGCCAAGA AAAGGGATA

-2160

-2080 TAGCGATTTT CGAAAATAGC CTCAACGGCG TAGAGAGTGC CAAAATAACT CTCAGACATG ACTATAGAAA GAAAAAATA

2000 ATATG

-1920 GGGGCTCCAA TTCATGTTGT GTGTGCCACT TATTTITTTC ACTGCGTACC AATAAAACAT CACAACACGC ATTATTCGG

-1840 GTGGACAACG AATATCCGAA CCATTAAAA GTCGTGTCT TTACAATTAC ATAAATGCAT GCTTATATCA TGGTAATAC

- 1760 GGGTGCATTT TCCGACATTT CAGTGCGTGG AGACACTGAC TTGACTTTTT CAAAGACATT TATAAGACAA ATTAAAGCGA

-1680 TTTAAATGAA TGTCCTGAAT AGATAAATCA ACTTCGTTAA CATTTATTTT AGAGGCAAAT GCATTTAGGA AGTTTTGGTA

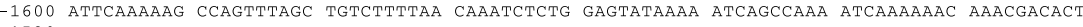

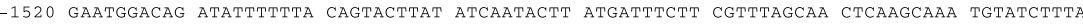

-1440 TTGAAGAaTg TTTAGATATT TTCAAAGGAa AgCAAAAATA GTGAAGAAAA TATCCATTGT TATTTATTTA TACATTTAAC

-1360 ACGTTTTGCT CACAATTAAg AaCTGTTTAA GATTGCAAAa ACCCCGAGgT AAATATCACC ACATACCTCA CTTTCATATT

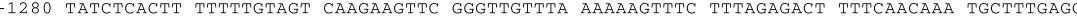

-1200 ATAAAAATCA GCCAAAATCA AAAAACAAAT GACAATGAAT GGACAGATAT TTGAACATAT GAAAACAAAA ATTAATTTCT

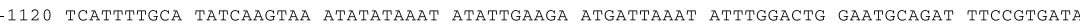

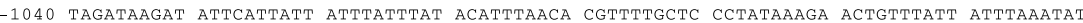

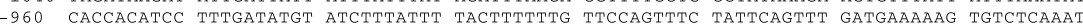

-880 ATACTGTGCC CTGATTCACT CTGGCCCTTA ACTTTTAATT TATTTTAATT TATTTATTTT TTGCTGCATG TGCAATACAT

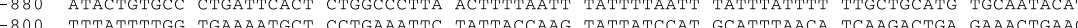

-800 TTTATTTTG TGAAAATGCT CCTGAAATTC TATTACAAG TATTATCCAT GCATTTAACA TCAAGACTGA GAAACTGAAC

-720 AAGATTAAGT GAGTTTTGCC CAAAATAAGA GCAAATATCT GTCAAAAGAT TAATTTCATT AACTTTTTAT AGTGTGATTA

-640 GCAGGTATTG AAACGTTATT GCAGTATTTT AGTTGGAAAG TTATTAAACT TTTTTAATGT TCGAATACTA AAATTTTATC

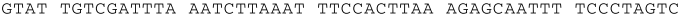

-480 TAAACATGTC TTAAAGAagt ATTACATTCA CCAAAGTCAC ACCTAAATAA CCAGAAACCT AAACCTACAT TGTTTTTGGT

-400 CTAAAATCGA ATATCACATC TGCTTAIACC AGTAAGT

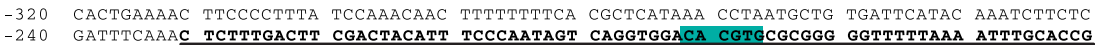

$\begin{array}{lll}-240 & \text { GATTTCAAAC TCTTTGACTT CGACTACATT TCCCAATAGT CAGGTGGACA CGTGCGCGGG GGTTTTTAAA ATTTGCACCG } \\ -160 & \text { AGAAGTGTTC TGGAGAAAGT GTGTCACTGG GCCACGAGTC GGGTCACATG GACACATTTC GAGCCTCGTG CAGCAGCAGT }\end{array}$

-80 GGAGTGTGGT GCGCCTGCGC GCATCTCCTC CATCCATGCT CGCAGCTAAG CAAAACCGGG CCGACTTGAC AGAACAGTTC

+1 AGAGCGATAC AGATTGGGCG AGTGACAGGA CAAGCGCACT GGCGTATGAT TGGCTTTCAC TGAatgaACC ATATTTCACT

+81 GGCGTCTTTG CGCAGATCTT TTCTTCTTAT AAAAGCAGAT GCGCACGTAT TTGGTGCGAC TTTAGGAAAT CAATTGCTTA

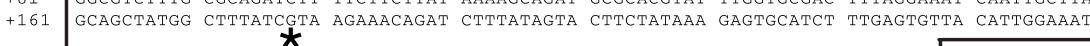

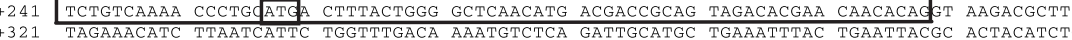
+401 TTTGGCAAAC AAAGTAAATG TATAACTGCG TGGTGCAGTG TGTTTTCTTA CTATCTGAAA TGAGTCTGCC AACATTTAAT +401 TTTGGCAAA AAAGTAAATG TATAACTGCG TGGTGCAGTG TGTTTTCTTA CTATCTGAAA TGAGTCTGCC AACATTTAAT +481 GAGAATCATT CTAAACAATA ATGAGTGATT TAATAACGTA CAAAAATATT TATTTGAAAG CCTACGTGCT TCTTATATGC +561 CATTACACAC GAGTCTTCAT ATGAGTGAAA TGAAAATGTT TGTTCAAGTA TGCATCATTT GCATATATAC ATCGTATTT +641 GCATAAGAaA TGGTTGCGGT ATGCATAAAA TGTAAATAAg GAACGAAGGC AGACATCACG GGTTAAGACA CAGTGTTCTC +721 ATGAATTTCG GGGAACTAGG TCATAACTGA AAAGTCAGGT GTACGGACAT CCCTGTGATG CAGGCGAGCG TCGATGGTTC +801 TCACTCGATT CACATGTACC GCCGAGTCTA GCCATGTGCT TTTIGTTTTC ATTCTCCGCT CTCCGCCTAC AGCTATTGG +881 AAACGCAGGC GCTCATACA TAATTCCGCC TTGCTTTGAG TCTGTCCTCC CAGCGCGAAC CCGTGTGTGA CGCTGCAGTC +961 TGAGCCATGT GCGCGCTGCG ATTGGACCGA ATAGTGAGAC TCGGGGCTGG ACATCACGTT AACCCGTGTT CACTTTGAAA +1041 GTGGGACATG AAATTGATCC AGTTTAACGT AACAGTTTTA CCCCACTCCC TGTGACATGA ACACAACGTC ACAAAATATC +1121 CCCGTCTTCC CGTTAACAGT ACATCTTATT TATGTTCTTA AATTAAAATC AGTTAGCATC GGTTTTCAAT GCACAAAACG

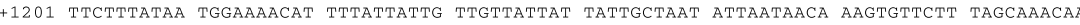

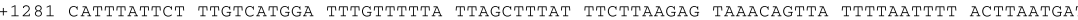

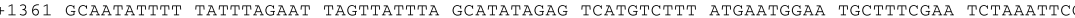

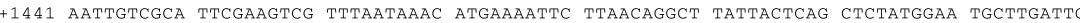

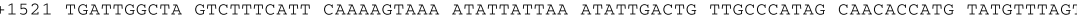
+1601 ATCTATACAg CCACAATAAC TGGCAGCTGA ATAATTTCAG TAATAGTTAT ATGTACACAC ACACACACAC ACACACACAC +1681 ACACACACAC ACACACACAC ACACGTGTAT TTCTCTCACG CATTCACACA CACACACAGA GATGGTAAGA AATGGAGAAA +1761 GAGGTGGGTC ATCCATTCAT ATTAAGAGAT TATATATACT AATGTTGGGT GGTAACCTAA TAGCCCTATT AAAgTGTGTT 1841 CCGGTGATCT GACATTTTAT CCAACCCATC 1921 CCGCGATATTAC ACCTTCATAC CACACTACTT CACATA +1921 ACGATATAT

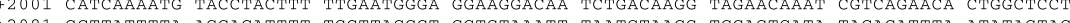
+2081 CCTTATTITA AGCACATTT TGCTTACCCT GGTGTAAATT TAATGTAACG TCCAGTGATA TACACATTTA ATATAGTAGA +2161 TGAGT +2241 GGCGGGTGTG TTCTGAGAGG CGTGTCTAAT GGAGTGAGTC TCGTTGAAAG GCCGTCCTTT GTGTGGCACA CGTGGAGAGQ +2321 AGGCGTGCTT CTACAGCACA CACGCGCCCC TGTCCTGCTT ACACAAGTAT TTCCTCTGAC AATGTTTTTG AGCACAAGAT +2401 CCGGAGCCAC TGTTGCCATG TAAAAATAAC ACAAACATTC TCAATGAACT CAGTTTAAAA CAGCCAGTGT AGTGGACAAG +2481 GACTGATACA TCCAACGCAT GACAGATGCT GTTCATGAGC ATTTGAGGCA GAACAGAGGA GATGAAGCTG AAACACGTTM

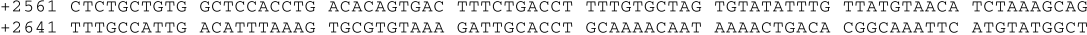

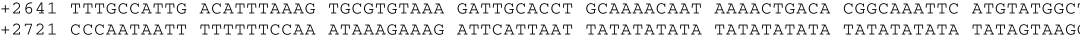

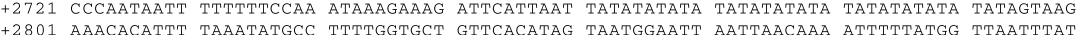
+2801 AAACACATTT TAAATATGCC TTTTGGTGCT GTTCACATAG TAATGGATT AATTAACAAA ATTTTTATGG THAATTTAT +2961 TTGATCCCTT TTAATGCACT TTATACATG CAAATAATAT ACATGCTATG GTCAATGCCA AACTGTAAAC TCTGGCACAC

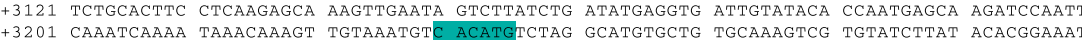
201 CARTCAAA TAAACAAGT TGTAAATGTC ACMT +3361 CACACACACT CAGGAAAAAA AGGAGTGGTT CTTGCAACTG TTTTTTTTTA TGTCCCTTAA CAGTTCCTAG AAAGTGTCTC

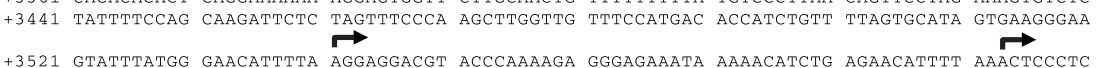
+3521 GTATTTATGG GAACATTTTA AGGAGGACGT ACCCAAAAgA GGGAGAAATA AAAACATCTG AGAACATTTT AAACTCCCTC

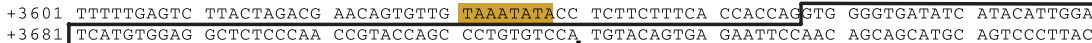

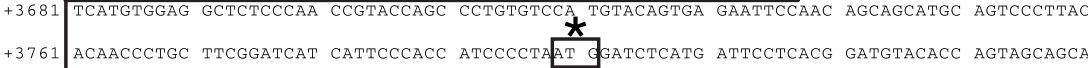

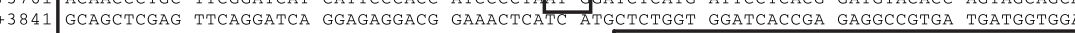

\section{Exon 2}

RevRE

RevDR2

E-box GCGC-like box

TATA-like box

$\rightarrow$ Transcriptional start site

*

Start codon

Figure 1 Sequence of the zfRev-erb $\alpha 5^{\prime}$ regulatory region. The two promoters ZfP1 and ZfP2 are indicated together with the transcriptional start sites as determined by RNAase protection (stars). The ATG in exons 1 and 2 are boxed. The main response elements discussed in the text are also indicated by different colors. The region which is highly conserved between zebrafish $\mathrm{P} 1$ and mammalian $\mathrm{P} 1$ is in italic. 
A
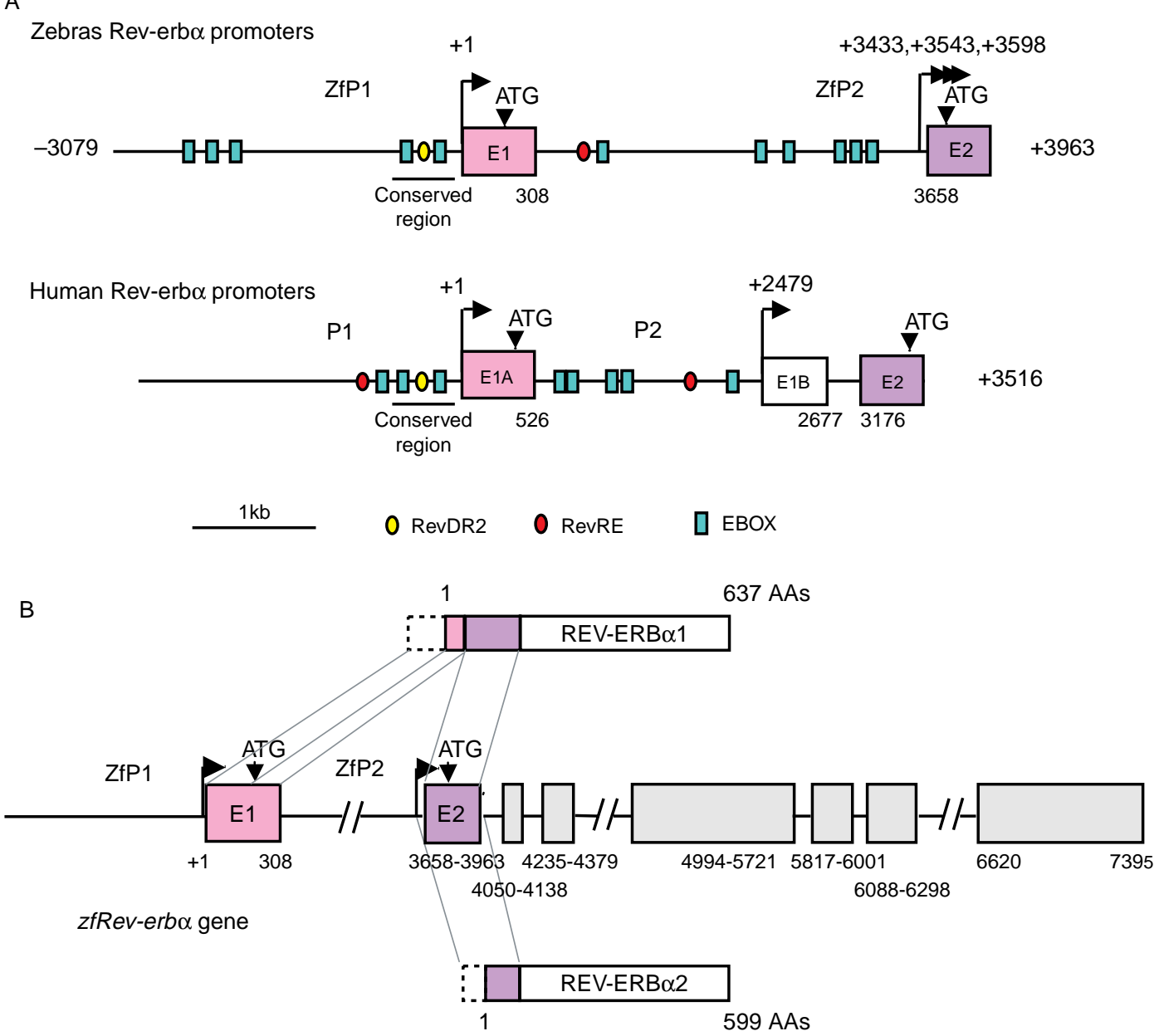

Figure 2 Intron-exon structure of the 5'-UTR of the zfRev-erb $\alpha$ gene. (A) Comparison of the zebrafish, human Rev-erb $\alpha$ promoter structures. The yellow and red circles indicate the different types of RevREs. The green rectangles indicate the putative E-boxes. Black lines under P1 promoters indicate the highly conserved region. (B) Schematic of the $z f R e v$-erb $\alpha$ gene and generation of the two $\mathrm{N}$-terminally distinct isoforms, zfREV-ERB $\alpha 1$ and zfREV-ERB $\alpha 2$, from two different promoters, ZfP1 and ZfP2. Numbers under the genomic scheme indicate the position of each exon. Transcription start sites are indicated by arrows. Untranslated sequences are shown as dotted squares and translated ones are shown as solid line squares. The amino acid number of each isoform is indicated. The accession number of ENSEMBL is ENSDARG00000033160.

amplified products (3215 and 3389 bp respectively) were subcloned into pCR2.1-TOPO and sequenced to check the absence of artifactual mutations. From these clones, a XhoI-BamHI fragment containing the Rev-erb $\alpha$ promoter was excised and subcloned into pGL2basic and pd2EGFP.

The primers used were as follows. In each case, the position of the primer in the sequence shown in Fig. 1 as indicated: ZfP1 $5^{\prime}$ primer: $5^{\prime}$-GAGAGCTCGCGGCCGCGAGCTC- $3^{\prime}$ (on $\lambda$ FIX II). ZfP1 $3^{\prime}$ primer: $5^{\prime}$-TCGTCGCACCAAATACGTGCGC-3' (positions +121 to +136 ). ZfP2 $5^{\prime}$ primer: $5^{\prime}$-CCGCTCGAGGACACGAACAACACAGGTAAGACGCTTT TAGAA- ${ }^{\prime}$ (positions +293 to +325). ZfP2 $3^{\prime}$ primer: $5^{\prime}$-TCGGGATCCGATCCAATGTATGATATCACCCCACCTGG TGGT-3' ${ }^{\prime}$ (positions +3650 to +3682 ).
Mutations of RevDR2 were produced by PCR using the following oligonucleotides. pRevDR2WT: $5^{\prime}$ primer: 5'-GAGCTCCTCTTTGACTTCGACTAC-3' (positions 231 to -214$) .3^{\prime}$ primer: $5^{\prime}$-GGATCCCGCACCAAATACG TGCGC-3' (positions +121 to +136 ). pRevDR2M5: $5^{\prime}$ primer: 5'-GTTCTGGAGAAAGTCCTAGCCTGGGCCACGAGTC-3' (positions -154 to -121 ). $3^{\prime}$ primer: 5'-GACTCGTGGCCCAGGCTAGGACTTTCTC-

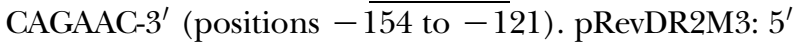
primer: 5'-GGAGAAAGTGTGTCACACCCGGTCGAGTCGGGT CAC-3' (positions -149 to -114 ). $3^{\prime}$ primer: 5'-GTGACCCGACTCGACCGGGTGTGACACACTTTCTCG-3' (positions -149 to -114). pRevDR2-M53: $5^{\prime}$ primer: 5'-GAGAAAGTCCTAGCCACCCGGTCGAGTCGGG TCACATG-3' $\overline{\text { (positions }}$ 
-148 to -111 ). $3^{\prime}$ primer: $5^{\prime}$-CATGTGACCCGACTCGACCGGGTGGCTAGGACTTTCTC-3' ${ }^{\prime}$ (positions -142 to -111$)$. The integrity of each construct was verified by sequencing of both strands.

\section{Cell culture, transient transfection, and reporter assays}

COS1 cells were grown in Dulbecco's modified Eagle's medium supplemented with $10 \%$ fetal calf serum, $100 \mathrm{U} / \mathrm{ml}$ penicillin, and $0.25 \mu \mathrm{g} / \mathrm{ml}$ streptomycin at $37^{\circ} \mathrm{C}$ in $7 \% \mathrm{CO}_{2}$. Transfection was carried out in COS1 cells using ExGen500 (Euromedex, France). Briefly, cells were plated in 24-well plates, $12 \mathrm{~h}$ prior to transfection. Luciferase reporter (100 ng) was co-transfected with the indicated expression vectors together with an expression vector encoding the $\beta$-galactosidase gene for normalization (pCMV-SPORT- $\beta$-gal vector; Life Technologies; Triqueneaux et al. 2004). After a 12-h incubation, the medium on the cells was replaced by fresh medium. Cells were harvested after 24-48 h for reporter assays. Luciferase activity was determined and is shown as relative light units normalized to the amount of $\beta$-gal activity. Each transfection was conducted in triplicate and data represent the mean \pm s.D. of at least three independent experiments.

\section{Electrophoretic mobility shift assays (EMSA)}

Synthetic oligonucleotides representing each strand of sequences were radiolabeled with 32-P- $\gamma$ ATP using polynucleotide kinase and purified on a polyacrylamide gel. Proteins were expressed using TNT reticulocyte lysate kit (Promega). Radiolabeled probes $(10 \mathrm{fmol}$, $20000-30000 \mathrm{cpm}$ ) were then incubated with binding proteins in $15 \mu \mathrm{l}$ reaction mixture containing $10 \mathrm{mM}$ KPO4 buffer (pH 8•0), 1 mM EDTA, $80 \mathrm{mM} \mathrm{KCl}, 1 \mu \mathrm{g}$ poly(dI-dC), $1 \mathrm{mM}$ dithiothreitol, $0.5 \mathrm{mM} \mathrm{MgCl} 2,5 \mathrm{mg}$ BSA, $10 \%$ glycerol, $1 \mathrm{mM}$ phenylmethylsulfonyl fluoride, $2 \mathrm{mg} / \mathrm{ml}$ aprotinin, $1 \mathrm{mM}$ leupeptin, and $1 \mathrm{mM}$ pepstatin. These reactions were incubated for $30 \mathrm{~min}$ at room temperature and analyzed on a $5 \%$ polyacrylamide gel in tris-borate-EDTA (TBE) buffer. Electrophoresis was performed at a constant voltage of $200 \mathrm{~V}$ at $4{ }^{\circ} \mathrm{C}$ in the same buffer. The oligonucleotides for EMSA were as follows: RevRE wildtype: $5^{\prime}$-TCTGGAGAAAGTGTGTCACTGGGCCACGAGTCGGGTCAC ATGGACACAT-3'. RevRE mutant: 5'-TCTGGAGAAAGTCCTAGCCACCCGGTCGAGTCGGGTCACATGGACACAT-3'.

\section{Zebrafish}

Zebrafish (Danio rerio) were kept at $28^{\circ} \mathrm{C}$ in a $14 \mathrm{~h}$ light:10 h darkness cycle (LD 14:10) with the light on at
$0900 \mathrm{~h}$ (ZT0) and the light off at $2300 \mathrm{~h}$ (ZT14). Adults were crossed overnight, resulting in spawning, and fertilization around ZT0 the next morning. Embryos were collected after spawning for MO injections and then raised at $28{ }^{\circ} \mathrm{C}$ in Petri dishes. To prevent pigmentation, $0.2 \mathrm{mM}$ 1-phenyl-2-thiourea (PTU; Sigma) was added to the water at $12 \mathrm{hpf}$.

\section{Whole mount in situ hybridization}

Embryos at $48 \mathrm{hpf}$ stage were fixed in $4 \%$ paraformaldehyde in PBS overnight at $4{ }^{\circ} \mathrm{C}$ and then stored in methanol. Whole mount in situ hybridization was performed as described by Thisse et al. (2004).

The zfRev-erb $\alpha$ exon 1 and 3 '-end probes for in situ hybridization were PCR amplified using the following primers and subsequently subcloned into pCSII + vector. Exon 1 probe: $5^{\prime}$ primer: 5'-TGAATGAACCATATTTCACT-3' (positions $61-80$ of the zfRev-erb $\alpha$ cDNA, see Fig. 1). $3^{\prime}$ primer: $5^{\prime}$-TGTGTTGTTCGTGTCTACTG-3' (positions 288-307). $3^{\prime}$-end common probe: $5^{\prime}$ primer: 5'-TCCCAACCGTACCAGCCCTG-3' (positions 346-365). $3^{\prime}$ primer: $5^{\prime}$-TTGTTGGGTGAATTGCGTGC-3' (positions 575-594).

All probes for zfRev-erb $\beta$ and $\gamma$ and the five $z f R O R$ genes are available to VL under request.

\section{MOs injections}

MOs were designed with sequences complementary to the cDNA encoding zfRev-erb $\alpha 1$ (MO1) and zfReverba2 (MO2) around the transcriptional start codon based on the recommendations of the manufacturer (GeneTools). The MO sequences were as follows: MO1: 5'-TGCAGGGTTTTGACAGAATTTCCAA-3' positions 234-257; see red boxes in Supplementary Fig. 2B. MO2: 5'-TGGACACAGGGGTGGTACGGTTGGG-3' positions 347-365.

For the control, we used the standard control MO from GeneTools: 5'-CCTCTTACCTCAGTTACAATTTAT- $3^{\prime}$. We injected the zebrafish wild-type embryos as described (Nasevicius \& Ekker 2000) at one- or two-cell stage with $0 \cdot 5-2$ pmol MOs diluted in sterile water (see Supplementary Materials and methods section).

\section{In vivo expression assays}

For microinjection of promoter constructs into zebrafish embryos, plasmid DNA was purified using a plasmid isolation kit (Qiagen). The DNA was diluted to a final concentration of $50 \mathrm{ng} / \mu \mathrm{l}$ in injection solution $(0 \cdot 1 \mathrm{M}$ $\mathrm{KCl}$ and $0.05 \%$ phenol red). Circular plasmid was injected into one-cell stage embryos with or without pSG5-r(rat) ROR $\beta$ expression vector using a microinjector (Femojet, Eppendorf). Injected embryos were 
raised at $28{ }^{\circ} \mathrm{C}$ in $\mathrm{E} 3$ medium $(5 \mathrm{mM} \mathrm{NaCl}, 0 \cdot 17 \mathrm{mM}$ $\mathrm{KCl}, 0 \cdot 33 \mathrm{mM} \mathrm{CaCl} 2,0 \cdot 33 \mathrm{mM} \mathrm{MgSO} 4,10-5 \%$ methylene blue) and were collected at different times after fertilization. The pGS5-rROR $\beta$ construct is a generous gift of Michael Becker-André.

\section{Fluorescent microscopy}

Embryos and larvae were anesthetized by immersing them in $0.017 \%$ 3-aminobenzoic acid ethyl ester methanesulfonate salt solution (Sigma) and then mounted in 3\% methyl cellulose (Sigma) or 4\% LMP agarose (Invitrogen) on glass slides. They were observed under a Zeiss upright fluorescence microscope (Axioplan2) equipped with a Zeiss filterset 10.

\section{Supplementary materials and methods}

\section{RNAase protection assay}

The RNase protection probes were amplified by PCR from the $\lambda$ FIX II genomic clone using the following primers: ZfP1: $5^{\prime}$ primer: $5^{\prime}$-CTCTTTGACTTCGACTAC$3^{\prime}$ (positions -231 to -214 ). $3^{\prime}$ primer: $5^{\prime}$-CGCACCAAATACGTGCGC-3' (positions +121 to +138 ). ZfP2: $5^{\prime}$ primer: 5'-CAGTTCCTAGAAAGTGTCTC-3' (positions +3421 to +3440$)$. $3^{\prime}$ primer: $5^{\prime}$-GATGATCCGAAGCAGGGTTG-3' (positions +3762 to +3781 ).

PCR products were cloned into pCR2.1-TOPO vector (Invitrogen). After linearization with BamHI, antisenselabeled RNA probes were transcribed with T7 polymerase (Roche). These 370 nucleotide- and 361 nucleotide-long probes contain sequences complementary to the $5^{\prime}$-flanking regions of the zfRev-erbs plus $42 \mathrm{bp}$ of the pCR2.1-TOPO vector (see Supplementary Fig. 1A). RNase protection analyses were carried out as previously described (Neel et al. 1995) using total RNA extracted from adult zebrafish liver at two different circadian time points.

\section{RT-PCR analysis}

Total zebrafish RNA was isolated from adult zebrafish liver by using Trizol Reagent (Invitrogen). The cDNA was prepared by reverse transcription of total RNA with random primers (Promega) and M-MLV reverse transcriptase (Invitrogen).

The RT-PCR analysis of the transcripts from the ZfP2 promoter was done with the following primers: Forward primers (upstream of exon 2, Supplementary Fig. 1B): F1: 5'-ACGTCTTCTTTCACCACCAGGTGGGGTGAT-3' (positions + 3638 to + 3667). F2: 5'-GTCTTACTAGACGAACAGTGTTGTAAATAT- $3^{\prime}$ (positions +3608 to +3637$)$. F3: 5'-CTGAGAACATTTTAAACTCCCTCTTTTTGA-3' (positions +3578 to
+3607). F4: 5'-CGTACCCAAAAGAGGGAGAAATAAAAACA- $3^{\prime}$ (positions +3548 to +3577 ). F5: 5'-GAAGTATTTATGGGAACATTTTAAGGAGGA-3' (positions +3518 to +3547 ).

Reverse primer (in exon 3): 5'-ACCTTGCACAGCAACACCATTCCATTCA-3' (positions +4053 to +4080 of the zfRev-erb $\alpha$ genomic fragment, see Fig. 1). PCR parameters were as follows: initial denaturation at $95^{\circ} \mathrm{C}$ for $10 \mathrm{~min}$ followed by 32 cycles of $1 \mathrm{~min}$ at $95^{\circ} \mathrm{C}, 30 \mathrm{~s}$ at $55^{\circ} \mathrm{C}, 40 \mathrm{~s}$ at $72^{\circ} \mathrm{C}$ with a final elongation at $72^{\circ} \mathrm{C}$ for $7 \mathrm{~min}$.

\section{Inhibition of translation in vitro by MOs}

The ability of each MO to specifically inhibit the translation of the relevant isoform was assessed by in vitro reticulocyte-lysate translation assay (Supplementary Fig. 2A). We performed in vitro translation of Rev-erb $\alpha 1$ and Rev-erb $\alpha 2$ using the Promega kit according to the manufacturer's instructions.

\section{Results}

\section{Characterization of the zebrafish Rev-erb $\alpha$ promoter}

In order to isolate the zebrafish Rev-erb $\alpha$ regulatory region, we screened a zebrafish genomic DNA library with a zfRev-erb $\alpha$ cDNA fragment encoding exons 1 and 2. We isolated and sequenced a genomic clone of $6.5 \mathrm{~kb}$ length including $3 \cdot 1 \mathrm{~kb}$ upstream of the first exon (Figs 1 and 2A). The sequence includes a region that is highly conserved between the zebrafish $\mathrm{P} 1$ promoter and the mammalian $\mathrm{P} 1$ promoter ( $61 \%$ sequence identity from positions -231 to -8 ; see Figs 1 and 2A; Triqueneaux et al. 2004). This region is located just upstream of zebrafish exon 1 suggesting that it may correspond to a promoter orthologous to mammalian P1. We used two probes ZfP1 and ZfP2 to determine the transcriptional start sites by RNAase protection assay. With one probe including exon 1 (ZfP1 probe), we observed two transcriptional start sites (as observed for mammals) at $-12 \mathrm{bp}$ and +1 upstream of the first coding exon 1 (Supplementary Fig. 1, panel A left). Since the Rev-erb $\alpha$ gene in mammals contains a second promoter downstream of exon 1 (Fig. 2A), we analyzed the 3'-region of the genomic zebrafish clone with the ZfP2 probe and the RNAase protection assay revealed several protected bands (Supplementary Fig. 1, panel A right). At least three transcriptional start sites could be detected upstream of exon 2 (about $-225,-115$, and $-65 \mathrm{bp}$ ). Importantly, most of these protected bands were confirmed by an RT-PCR analysis performed with an overlapping set of primers inside intron 1 (Supplementary Fig. 1B). Sequencing and computer analysis of this region revealed that a TATA-like box is present at 
-20 bp from exon 2 (+3631 in Fig. 1), which suggests that this region corresponds to a functional promoter. We next tested the transcriptional activity of the two genomic regions $(3.2 \mathrm{~kb}$ upstream of exon 1 and $3.4 \mathrm{~kb}$ upstream of exon 2 respectively) by fusing them to a luciferase reporter gene. These constructs were transiently transfected into COS1 cells. The activities of both constructs were about 20-fold higher than the PGL2 basic control (Fig. 3A). These values are similar to the

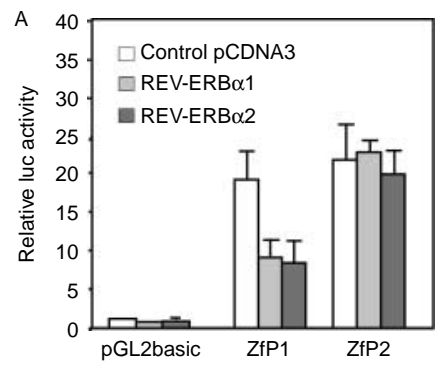

B -230
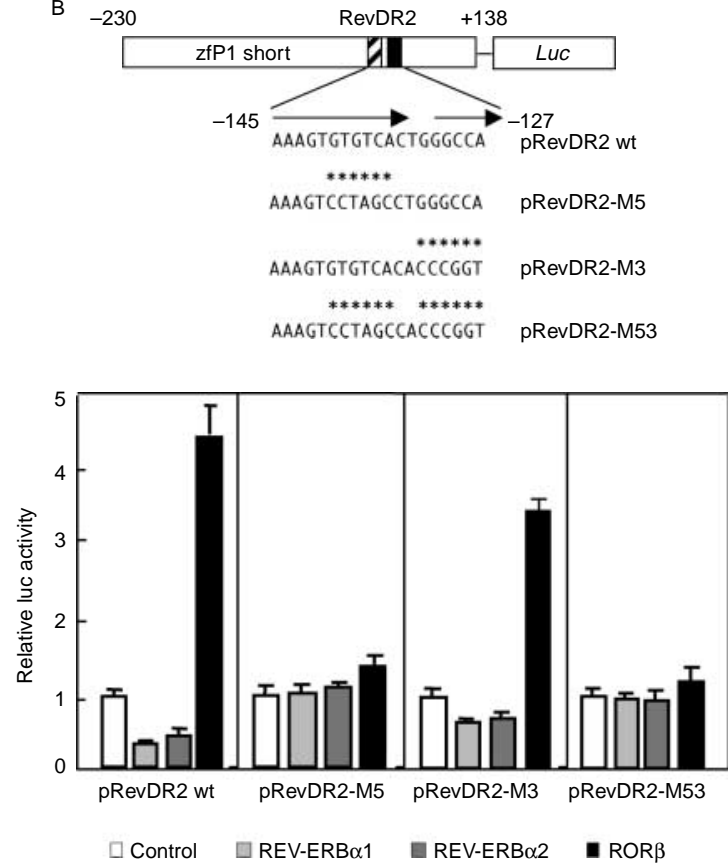

Figure 3 Transcriptional activity of the zfRev-erb $\alpha$ promoters. (A) COS1 cells were transfected with $100 \mathrm{ng}$ of a $3.2 \mathrm{~kb}$ ZfP1 (left) or a $3.4 \mathrm{~kb}$ ZfP2 (right) promoter luciferase reporter vector and $100 \mathrm{ng}$ Rev-erb $\alpha$ isoforms, Rev-erb $\alpha 1$ or Rev-erb $\alpha 2$ expression vectors. DNA amount of each transfection was adjusted by additional pCDNA3 control plasmid. (B) Mapping of the RevDR2 element in ZfP1. COS1 cells were transfected with $100 \mathrm{ng}$ indicated expression vector, zfRev-erb $\alpha 1$ zfRev-erb $\alpha 2$ ROR $\beta$ or empty pCDNA3 vector and ZfP1 luciferase reporter constructs (100 ng) containing the wild type or three different mutated versions of the RevDR2 element ( $-145 \mathrm{bp}$ to $-127 \mathrm{bp}$ ), pRevDR2-M5, pRevDR2-M3, or pRevDR2-M53. Relative luciferase activities are shown after normalization with an internal control of $\beta$-gal activity. Each transfection was done in triplicate and the data represent the mean \pm s.D. of at least three independent experiments. level of activity measured for the mammalian P1 and P2 promoters (data not shown; Triqueneaux et al. 2004).

Taken together, these results strongly suggest that the $6.5 \mathrm{~kb}$ zfRev-erb $\alpha 5^{\prime}$-flanking region contains two genuine promoters that we call ZfP1 and ZfP2. Since exons 1 and 2 each contain an initiation codon in frame to the main ORF of the cDNA, these two promoters can generate two isoforms with distinct N-termini: a long one of 637 amino acids called zfREV-ERB $\alpha 1$, from ZfP1, and a short one of 599 amino acids called zfREV-ERB $\alpha 2$, from ZfP2 (Fig. 2B). Of note, ZfP1 can also generate the zfREV-ERB $\alpha 2$ isoform by alternative translation initiation of the mRNA. This situation is reminiscent of the mammalian Rev-erb $\alpha$ gene organization except that in mammals the $\mathrm{P} 2$ promoter is upstream of a noncoding exon 1 (Fig. 2A).

\section{Characterization of a functional Rev-erb $\alpha$ regulatory element (RevDR2) in the ZfP1 promoter}

The sequence of the two promoters revealed that a potential RevDR2 element is present at positions -145 to $-127 \mathrm{bp}$ of $\mathrm{ZfP} 1$ promoter. This element is located in the conserved region of the promoter. In addition, a non-conserved monomeric RevRE element is present upstream in ZfP2. To investigate the roles of these elements, ZfP1 or ZfP2 reporter constructs and expression vectors encoding the long or short isoforms of zfRev-erb $\alpha$ were co-transfected into COS1 cells. As shown in Fig. 3A, ZfP1 was repressed by both isoforms of zfREV-ERB $\alpha$ with the same efficiency, whereas ZfP2 activity was not influenced by zfREV-ERB $\alpha$. This suggests that REV-ERB $\alpha$ regulates its own expression through the RevDR2 element of ZfP1, but does not recognize the monomeric RevRE in ZfP2. This also shows that both zebrafish REV-ERB $\alpha$ isoforms are potent transcriptional repressors.

To investigate the role of the RevDR2 site, we constructed a short version of the ZfP1 $(-230$ to +138 bp; Fig. 3B, upper). To directly test the importance of the RevDR2 sequence, mutations were introduced into the $5^{\prime}$ half-site of the RevDR2 (M5), the $3^{\prime}$ half-site (M3), or of both the $5^{\prime}$ and $3^{\prime}$ half-site (M53). The basal promoter activity was not significantly affected by mutations in the RevDR2 element (data not shown). As shown in Fig. 3B, the shorter ZfP1 construct was still significantly repressed by zfREV-ERB $\alpha 1$ and zfREV-ERB $\alpha 2$. Interestingly, and as expected, this construct was also activated by $\operatorname{rROR} \beta$ expression, as the full-size ZfP1 reporter constructs (Fig. 3B; data not shown). In contrast, when the mutants M5 or M53 were used, ZfP1 activity was not influenced by zfREV-ERB $\alpha$ (either $\alpha 1$ or $\alpha 2$ ) or $\operatorname{rROR} \beta$. On the other hand, a small repression by REV-ERB $\alpha$ and an activation by rROR $\beta$ were observed when the M3 mutant was used. This result was expected since 
this mutant still includes a bona fide monomeric RevRE sequence. To validate this observation, we carried out EMSA experiments using a labeled RevDR2 element and in vitro translated zfRev-erb $\alpha$ and rROR $\beta$ proteins (Fig. 4). As expected, these data show that zfRev-erb $\alpha$ and $\operatorname{rROR} \beta$ bind to the wild-type zfRevDR2 site, whereas the DNA binding was almost abolished when mutations were introduced in the $5^{\prime}$ and $3^{\prime}$ AGGTCA motifs.

Taken together, these results indicate that $\mathrm{ZfP} 1$ is regulated by zfRev-erb and rROR through a zfRevDR2 site and that an intact RevDR2 element is required for the ROR-mediated activation and Rev-erb-mediated repression of Rev-erb $\alpha$.

\section{The zfRev-erb $\alpha$ gene is regulating its own transcription} in vivo

It has been previously reported that zebrafish Rev-erb $\alpha$ is expressed in pineal gland, retina, and optic tectum during early embryonic development and that its expression follows a circadian rhythm (Delaunay et al.

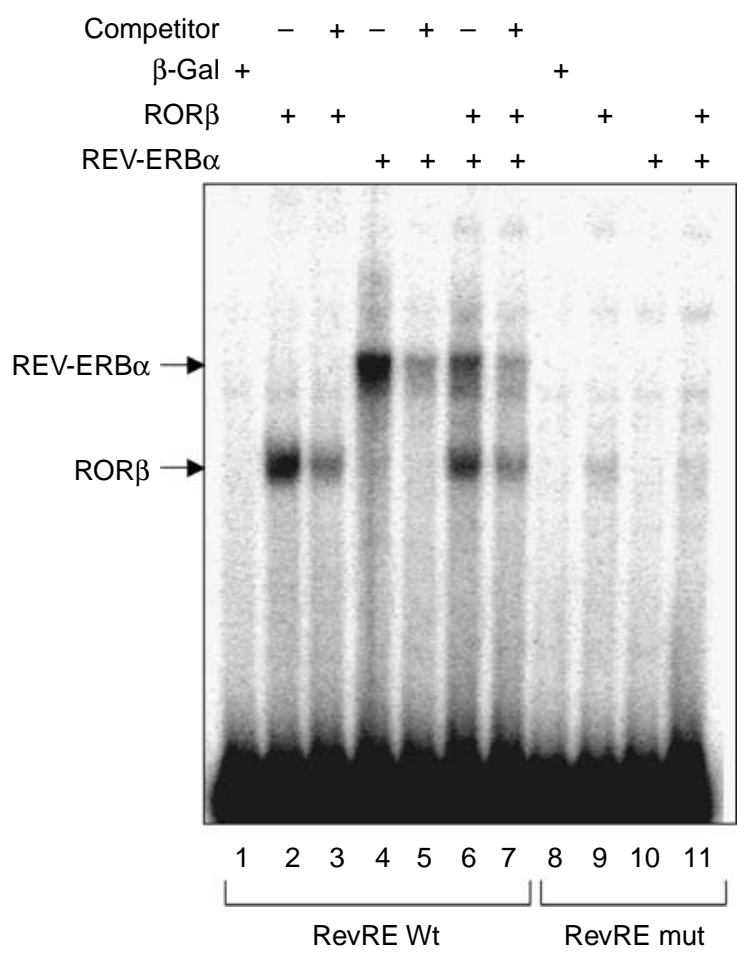

Figure 4 Both zfREV-ERB $\alpha$ and ROR $\beta$ bind to the RevRE site within the zfRev-erb $\alpha$ gene promoter. Electrophoretic mobility shift analyses were performed using in vitro translated zfRev-erb $\alpha$, $\mathrm{ROR} \beta$, and $\beta$-gal protein with radiolabeled wild type or mutated probes containing the RevDR2 site located in -152 to $-103 \mathrm{bp}$ of the zfRev-erb $\alpha$ promoter. The mutated probe corresponds to RevRE M53 sequence. Positions of zfREV-ERB $\alpha$ and $\mathrm{rROR} \beta$ binding are indicated by arrows. The competition experiments were performed by adding a tenfold molar excess of the unlabeled wild-type RevDR2 oligonucleotide (lanes 3, 5, and 7).
2000). We have recently shown that the pineal expression of zfRev-erb $\alpha$ depends on CLOCK and BMAL1 that directly interact with an E-box located in the ZfP1 promoter (Triqueneaux et al. 2004). To elucidate the effects of zfRev-erb $\alpha$ on its own gene expression in vivo, we used $\mathrm{MO}$ antisense oligonucleotides (MO) to prevent Rev-erb $\alpha$ mRNA translation (Nasevicius \& Ekker 2000). We designed two different MOs, each specifically targeting the translation of a distinct isoform of Rev-erb $\alpha$ (see Supplementary Fig. 2A and $\mathrm{B}$ ). Thus, MO1 and MO2 were used to inhibit the expression of zfRev-erb $\alpha 1$ and zfRev-erb $\alpha 2$ respectively. We confirmed that the protein synthesis of each of the zfRev-erb $\alpha$ isoforms was effectively inhibited by these MOs in an in vitro translation system (Supplementary Fig. 2A). We focused our analysis on the earliest zfReverb $\alpha$ expression, which starts in the pineal gland at $24-\mathrm{h}$ development and becomes prominent at 48-hpf. To distinguish the expression of each isoform of Rev-erb $\alpha$, we compared the signal generated by two probes that have the same size ( $250 \mathrm{bp})$ : an exon 1 probe, specific of zfRev-erb $\alpha 1$, and a common $3^{\prime}$ probe that recognizes both zfRev-erb $\alpha 1$ and zfRev-erb $\alpha 2$ mRNA. Using these two probes, we found that Rev-erb $\alpha 1$ transcripts are barely detectable in the pineal gland, whereas they are found at later stages in retina and optic tectum (Fig. 5A; data not shown). In contrast, the common probe recapitulates the known expression pattern of the gene (Fig. 5F; data not shown). This result suggests that it is mainly Rev-erb $\alpha 2$ that is expressed in the pineal gland.

The injection of the control MO at the one-cell stage did not modify the expression of Rev-erb $\alpha$ mRNA in the pineal gland at $48 \mathrm{hpf}$ (Fig. 5B and G). In contrast, the injection of MO1 that inhibits translation of zfRev-erb $\alpha 1$ mRNA significantly increases expression levels of zfReverb $\alpha 1$ mRNA (Fig. $5 \mathrm{C}$ and H). No effect on Rev-erb $\alpha 1$ was observed when the MO2 was injected (Fig. 5D and I). The injection of both MOs also leads to an increase of zfRev-erb $\alpha 1$ mRNA expression (Fig. 5E). Essentially identical results were observed when the expression of both isoforms was monitored using a common probe (Fig. 5F-J): MO1 led to a clear increase of zfRev-erb $\alpha 1$, whereas MO2 seems to have no clear effect and MO1 plus MO2 show the same effect than MO1 alone. Nevertheless, these results should be interpreted keeping into account that our detection of the transcripts emanating from ZfP2 is only indirect, with a common probe detecting both isoforms. As expected, the expression of Otx5 mRNA (used as a control) was not altered by any of the MO injections (Fig. 5K-O; Gamse et al. 2002). These data show that the knockdown of zfRev-erb $\alpha$ with MO1 increases the expression of Reverb $\alpha$ itself in vivo suggesting that in the pineal gland, the zfRev-erb $\alpha 1$ expression is efficiently repressed by zfReverb $\alpha 1$, but not by zfRev-erb $\alpha 2$. 


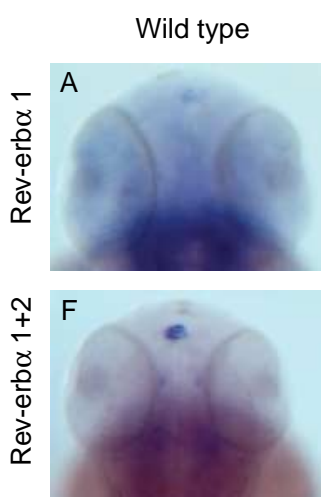

Control MO
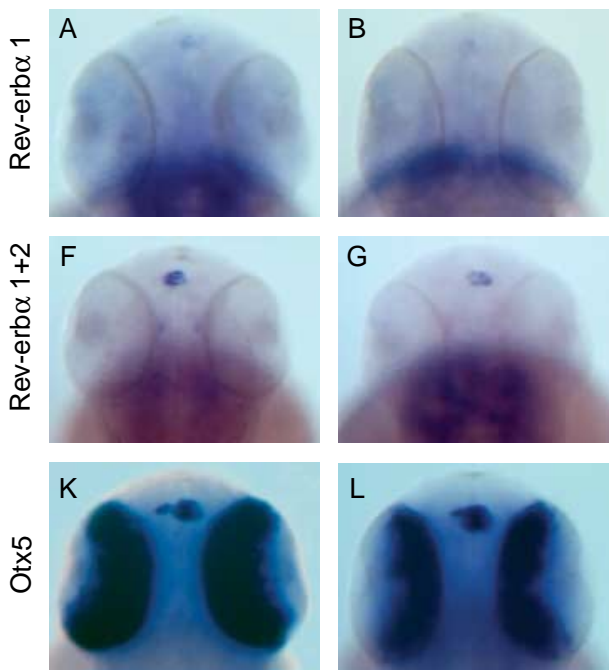

Rev-erb $\alpha 1$ probe

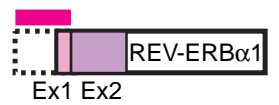$$
\text { Ex1 Ex2 }
$$

MO1
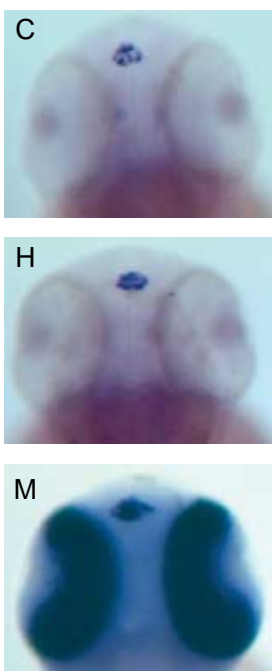

Rev-erb $\alpha 1+2$ probe

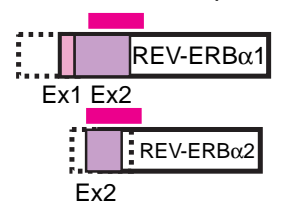

Ex2
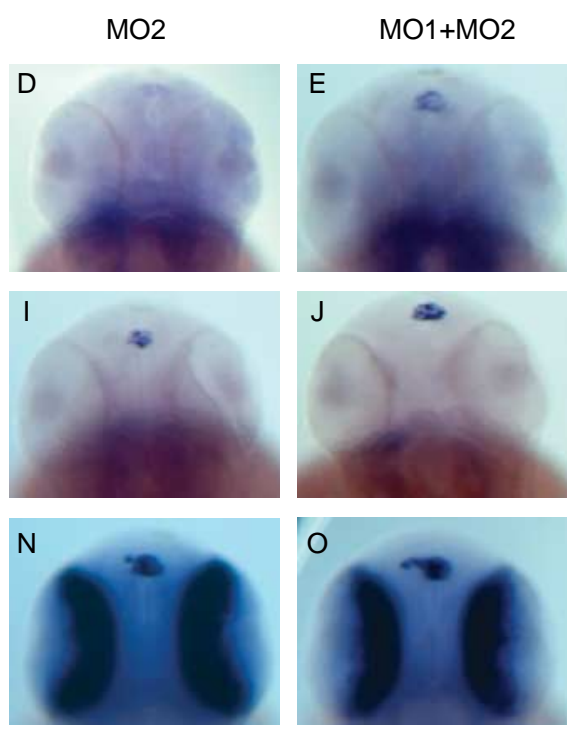

Figure 5 Whole mount in situ hybridization analysis of Rev-erb $\alpha$ expression in the pineal gland. The wild-type embryos $(A, F$, and $K)$, control $(B, G$, and $L), M O 1(C, H$, and $M), M O 2(D, I$, and $N)$, or MO1 + MO2 (E, J, and O) morpholinoinjected embryos were analyzed by whole mount in situ hybridization at $48 \mathrm{hpf}$. (A-E) Expression of Rev-erb $\alpha$ was analyzed using a Rev-erb 1 specific probe designed in exon 1 (see the scheme below the figure; left). (F-J) Expression of Rev-erb $\alpha$ analyzed by a common $3^{\prime}$-end probe that recognize both Rev-erb $\alpha 1$ and Rev-erb $\alpha 2$ transcripts (see the scheme below the figure; right). (K-O) The expression of Otx5 at $48 \mathrm{hpf}$ in embryos was analyzed as a control for normal pineal gland development. Embryos were raised in $14 \mathrm{~h}$ light:10 h darkness (LD 14:10) conditions. At ZTO (0900 h when the light is on), embryos were fixed.

\section{Rev-erb $\alpha$ and $R O R$ relationships in vivo}

Our transient transfection experiments clearly show that in addition to be controlled by zfREV-ERB $\alpha$ itself, zfRev-erb $\alpha$ expression is activated by rRORs. To gain insights into the in vivo relevance of this observation, we first decided to compare the expression patterns of zfRev-erb $\alpha$ with those of other Rev-erb and ROR genes present in the zebrafish genome. We have performed a systematic screen for the expression of all NRs genes present in zebrafish (SB and VL in preparation) and we found five Rev-erb genes (one Rev-erb $\alpha$, two Rev-erb $\beta$, and two Rev-erby; see Bertrand et al. 2004) and five ROR genes (two $R O R \alpha$, one $R O R \beta$, and two $R O R \gamma$ ). The large number of genes is explained by the ray-finned fish specific genome duplication that occurred early on during the evolution of actinopterygians (Jaillon et al. 2004) as well as by the selective loss of several $N R$ genes at the base of the mammalian lineage (Bertrand et al. 2004). Figure 6 shows the expression patterns of these genes at 48 hpf. One can observe that Rev-erb $\alpha$, Reverb $\beta$-A, Rev-erb $\beta$-B, and Rev-erb $\gamma-B$ are all expressed in the retina, the optic tectum, the hindbrain, and the pineal (Fig. 6, top panels A-C and E), whereas Reverb $\gamma$-A (Fig. 6, top panel D) is ubiquitously expressed in the head. All $R O R$ genes $(R O R \alpha-A, R O R \alpha-B, R O R \beta$, $R O R \gamma-A$, and $R O R \gamma-B$; Fig. 6 bottom F-J) are expressed at $48 \mathrm{hpf}$ in the retina and the optic tectum. In addition, ROR $\alpha-\mathrm{B}$ and ROR $\beta$ transcripts can be detected in the cerebellum, ROR $\beta$ being also expressed in the lateral line neuromasts. ROR $\gamma$-A transcripts are also detected in pineal. We noticed that four out of the five Rev-erb genes and all the $R O R$ genes are expressed in retina and optic tectum. Moreover, except in the hindbrain, $R O R$ genes are expressed in all territories, whereas Rev-erb genes show a restricted expression (Table 1). These expression data strongly suggest that in vivo zfRev-erb $\alpha$ expression can effectively be controlled by ROR genes.

To assess if this regulation occurs in an in vivo context, we cloned the ZfPland ZfP2 promoters upstream of a GFP reporter gene and injected them into early embryos in the presence or absence of a rat ROR $\beta$ expression vector. We observed that when injected alone, ZfP1 induces GFP expression in $2.5 \%$ of the 201 injected fishes, mainly in the retina as well as 

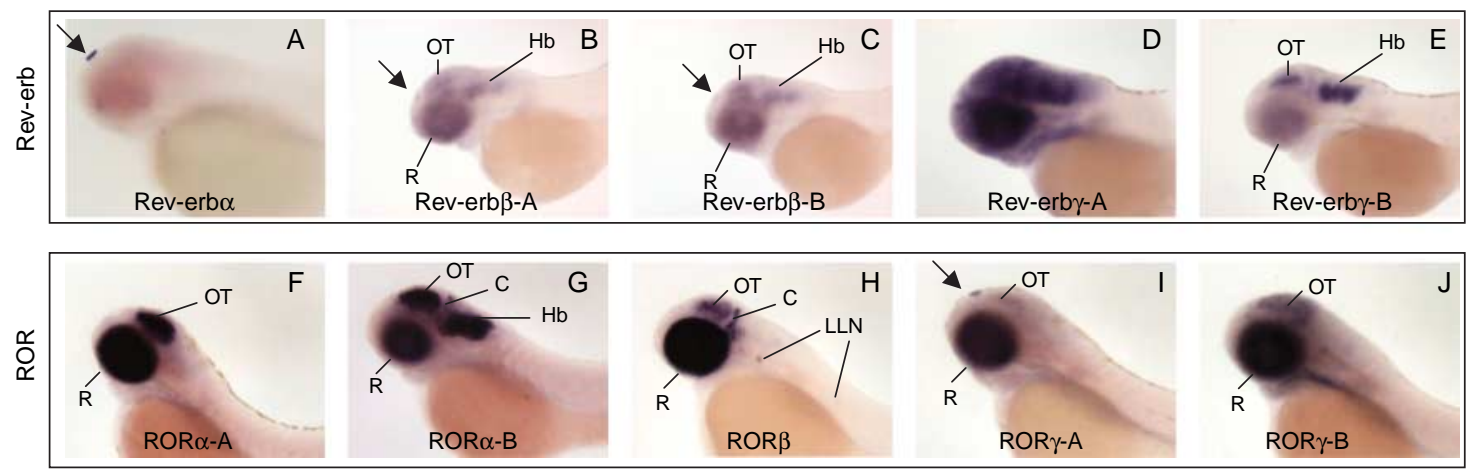

Figure 6 Expression patterns of Rev-erbs (upper) and RORs (bottom) transcripts in $48 \mathrm{hpf}$ zebrafish embryos. Lateral views of the head, anterior to the left. Arrows indicate expression in the pineal gland. (A) Rev-erb $\alpha$ is expressed in pineal gland (arrow). (B and C) Both Rev-erb $\beta$ genes are expressed in retina (R), optic tectum (OT), hindbrain (Hb), and pineal gland, the expression level seems weaker than that of Rev-erb $\alpha$. (D) Rev-erb $\gamma-A$ transcripts are found ubiquitously in the head. (E) Rev-erb $\gamma$-B is expressed weakly in retina, optic tectum, and more strongly in the hindbrain. No pineal expression was detected. (F) ROR $\alpha$-A has a very specific expression pattern in retina and optic tectum. (G) ROR $\alpha$-B is expressed similarly in retina and optic tectum plus in hindbrain and cerebellum. $(\mathrm{H})$ The unique $R O R \beta$ gene is mainly expressed in retina and more weakly in optic tectum, cerebellum, and lateral line neuromasts (LLN). (I) ROR $\gamma-A$ is the only ROR expressed in the pineal gland. It is also found in retina and weakly in the optic tectum. (J) ROR $\gamma$-B transcripts are localized in retina and optic tectum. Embryos were raised in $14 \mathrm{~h}$ light:10 h darkness (LD 14:10) conditions. At ZT0 (0900 h when the light is on), embryos were fixed.

in olfactory bulbs, brain, optic tectum at $60 \mathrm{hpf}$ (see Fig. 7). This scattered expression pattern is explained by the strong mosaicism after injection of reporter constructs into zebrafish embryos (Gibbs \& Schmale $2000)$. In the presence of ROR $\beta$, we found a significant increase $(5.7 \%$ at $36 \mathrm{hpf}$ and up to $23.4 \%$ when observed at $60 \mathrm{hpf}$ ) of GFP positive cells driven by ZfP1. In contrast, we did not note any effects of ROR $\beta$ on ZfP2 (Fig. 7A). This suggests that ROR $\beta$ acts, in vivo, as a potent activator of ZfP1 but not of ZfP2.

\section{Discussion}

In this paper, we show that Rev-erb $\alpha$ expression in zebrafish is controlled by two promoters that differentially regulate its expression. In addition, these promoters control the formation of two N-terminally different isoforms: ZfPI generates a transcript that encodes for Rev-erba1 (the longer form) and can, by alternative translation through an internal AUG sequence, also generate the shorter Rev-erb $\alpha 2$. In contrast, ZfP2 controls the expression of Rev-erb $\alpha 2$ only. This situation is reminiscent to what has been found in mammals, where two isoforms generated by alternative promoter usage and/or alternative translation have also been described (Triqueneaux et al. 2004). Interestingly, our data also reveal that ZfP1 is evolutionary conserved, whereas ZfP2 is divergent and regulated in a different way in mammals and fish.

\section{Evolutionary considerations}

Several lines of evidence suggest that ZfP1 is orthologous to its mammalian counterparts: i) there are about $60 \%$ sequence identity in the proximal region between the mammalian and fish promoters; ii) the main sites controlling the expression of the gene (the E-box in which the circadian CLOCK-BMAL1 complex binds and the RevDR2) are conserved and organized in a very similar way; and iii) functionally, these

Table 1 Tissue specific expression of zebrafish Rev-erb and ROR genes at $48 \mathrm{hpf}$

\section{Gene}

\begin{tabular}{|c|c|c|c|c|c|c|c|c|c|c|}
\hline & \multicolumn{5}{|c|}{ Rev-erb } & \multicolumn{5}{|c|}{ ROR } \\
\hline & $\alpha$ & $\beta-A$ & $\beta-B$ & $\gamma-A$ & $\gamma-B$ & $\alpha-A$ & $\alpha-B$ & $\beta$ & $\gamma-A$ & $\gamma-B$ \\
\hline \multicolumn{11}{|l|}{ Tissue } \\
\hline Pineal gland & ++ & + & + & $\mathrm{u}$ & - & - & - & - & ++ & - \\
\hline Retina & - & + & + & $\mathrm{u}$ & + & ++ & ++ & ++ & ++ & ++ \\
\hline Optic tectum & - & + & + & $\mathrm{u}$ & + & ++ & ++ & ++ & + & + \\
\hline Hindbrain & - & + & + & $\mathrm{u}$ & ++ & - & ++ & - & - & - \\
\hline
\end{tabular}

++ , Strong expression; +, weak expression; u, ubiquitous expression; -, no expression. 

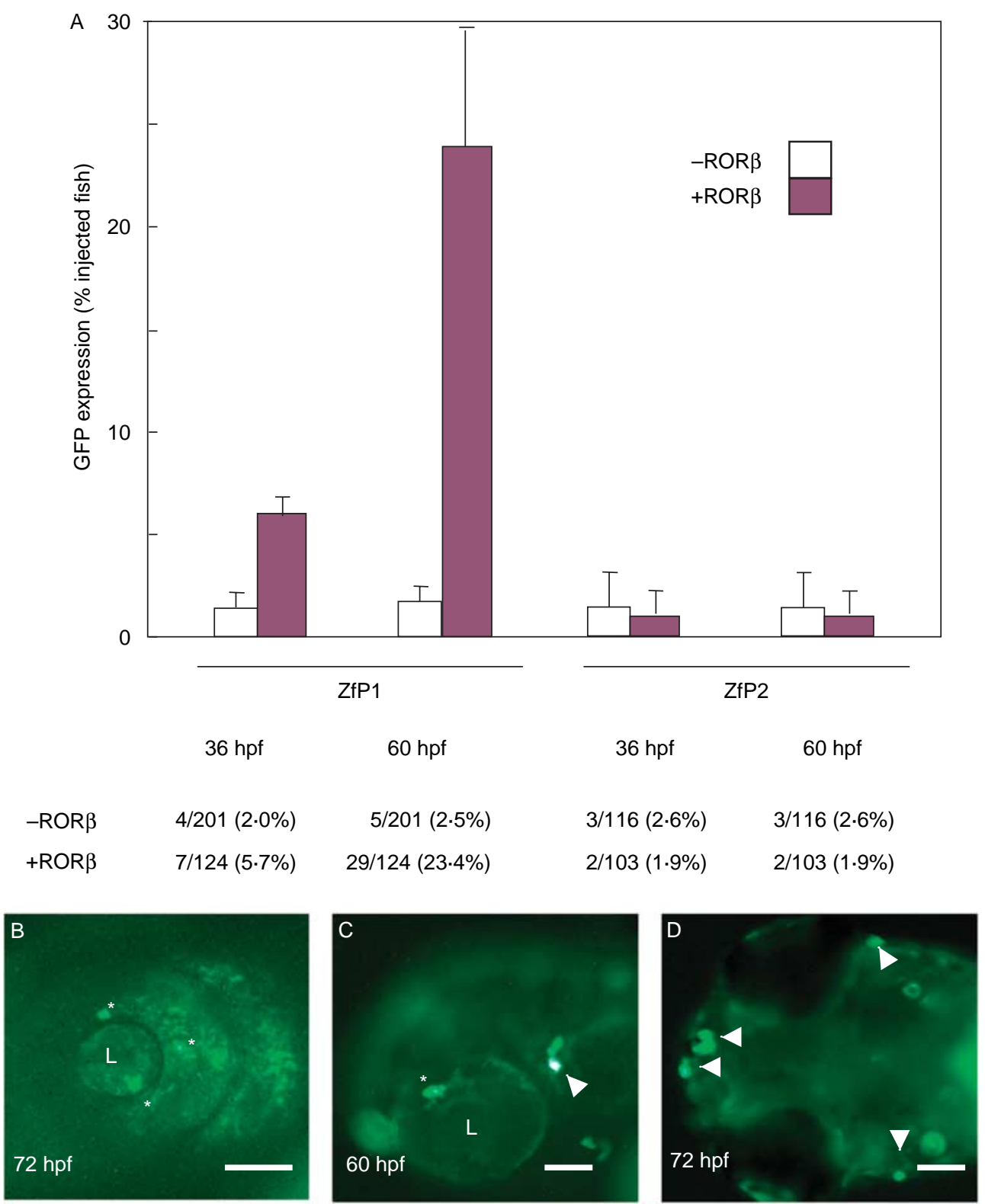

Figure 7 ROR $\beta$ controls zfRev-erb $\alpha$ expression in vivo. (A) Quantitative results of in vivo microinjection of ZfP1 or ZfP2 (white bars) and co-injection with ROR $\beta$ expression vector (colored bars) into one-cell stage embryos. A much higher proportion of ZfP1 and ROR $\beta$ co-injected embryos exhibit EGFP expression at either 36 or $60 \mathrm{hpf}$. ZfP2 promoter activity is very weak irrespective of the co-injection of a ROR $\beta$ expression vector. Quantitative results are indicated below the histogram. (B-D) Three representative examples of GFP positive fish showing GFP expression in retina ( $B$ and $C$ ) as well as in other locations $(C$ and $D)$, such as olfactory bulbs and otic capsule. These three fishes were co-injected with ZfP1-GFP and ROR $\beta$ expression vectors. (B and C) Anterior is to the left and dorsal is up. The asterisk indicates retinal cells that show strong GFP expression. Arrowheads indicate retina nonspecific GFP expression. (D) Dorsal view. L, lens. Scale bar $=50 \mu \mathrm{m}$.

regulations are conserved in vivo as well as in vitro. Such a degree of conservation between mammals and fish promoters is not frequent and further highlights the importance of the regulations we characterized in this paper.
In contrast, sequence comparison suggests that the $\mathrm{P} 2$ promoter in mammals and fish are very different. First, the structural organization of the zebrafish Reverb $\alpha$ gene exhibits some differences with its mammalian ortholog. If two alternative promoters generating two 
isoforms are present in both species, the position of the second promoter is different. In mammals, $\mathrm{P} 2$ is present upstream of an alternative non-coding exon E1B, whereas the ZfP2 is located directly in front of exon 2. Secondly, the regulation of the two promoters is different. In mammals, P2 is regulated by Rev$\mathrm{erb} / \mathrm{ROR}$, whereas none of these regulators act on zebrafish P2. In contrast, we observed that ZfP2 is regulated by Otx factors, whereas mammalian P2 promoters are not (Nishio et al. submitted). All these data suggest that the P2 promoters from fish and mammals are not orthologous or have strongly diverged.

Sequence comparison and functional analysis of the Rev-erb $\alpha 1$ and Rev-erb $\alpha 2$ proteins clearly suggest that the zebrafish and mammalian isoforms are very similar. The two isoforms are closely related in terms of their DNA binding and repression activity. This suggests that if there are functional differences, they are probably quite subtle. Both Rev-erb $\alpha 2$ correspond to truncations of an N-terminal part of the A/B region that notably contains some essential phosphorylation sites (Yin et al. 2006). In mammals, the Rev-erb $\alpha 2$ isoform, which is truncated in its NH2 extremity, is not phosphorylated in this region of the protein and hence exhibits a much higher stability (data not shown). It is an interesting evolutionary situation that divergent alternative promoters control the expression of evolutionary conserved isoforms. One explanation for this situation may be linked to the strong pineal expression of $\mathrm{ZfP} 2$, since it is well known that the function of the pineal gland has been drastically modified between early vertebrates, such as teleost fishes and mammals (see Nishio et al. submitted). It is clear that more work has to be done to really understand the biological role in vivo of the Rev-erb $\alpha 2$ isoforms in both mammals and zebrafish.

\section{The ZfP1 promoter is the target of Rev-erb $\alpha$ autoregulation}

In the ZfP1 promoter, we found at position -145 a classical RevDR2 element, which is located in the conserved region of the promoter. It is known that Rev-erb $\alpha$ and ROR receptors recognize similar response elements with a $5^{\prime}$ A/T-rich region and a A/GGGTCA motif, while they have opposite effects on gene transcription (Forman et al. 1994, Giguere et al. 1994, Retnakaran et al. 1994). We demonstrated that this element confers the Rev-erb $\alpha /$ ROR responsiveness (repression and activation respectively). We have also shown that Rev-erb $\alpha$ and ROR can directly bind to this RevRE in EMSA. Thus, as previously discussed, the sequence, position, and function of this RevDR2 appear to be highly conserved in vertebrates. Its close proximity to the neighboring E-boxes that mediate the activation of Rev-erb $\alpha$ by CLOCK-BMAL1 suggests that some sort of crosstalk may occur between the regulation of the Rev-erb $\alpha$ gene by Rev-erb/ROR and CLOCK-BMAL1. This hypothesis remains to be addressed experimentally.

We have previously shown in mammals that the Rev$\operatorname{erb} \alpha \mathrm{P} 1$ promoter is down-regulated by the Rev-erb $\alpha$ protein through its binding to the RevDR2 element (Adelmant et al. 1996). The in vivo relevance of this regulation was questioned when Rev-erb $\alpha$ knockout mice were generated that show no obvious changes in Rev-erb $\alpha$ gene expression (Chomez et al. 2000). Our results demonstrate that the knockdown of zfRev-erb $\alpha$ with MOs results in the accumulation of Rev-erb $\alpha$ transcripts in the pineal. This accumulation suggests that Rev-erb $\alpha$ represses its own transcription in vivo. The MO targeting Rev-erb $\alpha 1$ induced an accumulation of the transcripts from ZfP1, which is consistent with the idea that it is the RevDR2 site in ZfP1 that is instrumental for this regulation. Since there is no specific probe to visualize the transcripts emanating from $\mathrm{ZfP} 2$, it is not possible to know if the activity of ZfP2 is also modulated by MO injection. Nevertheless, given the results of our transient transfection assays showing that ZfP2 is not regulated by Rev-erb $\alpha$, modulation of $\mathrm{ZfP} 2$ activity by the $\mathrm{MO}$ injections appears highly unlikely.

In sharp contrast, when we injected MO2 targeting Rev-erb $\alpha 2$ expression, we did not note any effects on the Rev-erb $\alpha$ transcripts. These data suggest that, in terms of Rev-erb $\alpha$ autorepression, during early embryogenesis in the pineal gland, Rev-erb $\alpha 1$ plays a more important role than Rev-erb $\alpha 2$. This is quite surprising given the expression patterns that we observed at $48 \mathrm{hpf}$, when in the pineal zfRev-erb $\alpha 1$ is much less expressed than zfRev-erba2. Obviously, there is still a lot of work to be done to elucidate the respective roles of Rev-erb $\alpha 1$ and Rev-erb $\alpha 2$ and the crosstalk regulation of their expression during zebrafish embryogenesis.

\section{RORs regulates Rev-erb $\alpha$ expression}

Our results also show that ROR $\beta$ is able to activate the expression of Rev-erb $\alpha$ in the RevDR2-dependent manner and strongly suggest that this regulation occurs in vivo. We did not note an expression of the ZfP1 construct in the pineal gland, but this was not surprising given the highly mosaic activity of exogenous promoters in zebrafish using transient GFP expression assay (Gibbs \& Schmale 2000). Interestingly, no effect of ROR $\beta$ expression vector injection was found on ZfP2 promoter. This suggests that in vivo RORs activate only $\mathrm{ZfP} 1$. This is in general agreement with the fact that (according to our in situ hybridization data with isoform specific probes) ZfP2 appears to be specifically active in the pineal gland, whereas ZfP1 is apparently more 
active in the retina (Fig. 5; data not shown). Given the strong expression of $R O R$ genes in retina, if $\mathrm{ZfP} 2$ would have been regulated by RORs, then a specific mechanism would be necessary to explain its lack of activity in retina.

The expression patterns of the five Rev-erb and the five $R O R$ genes clearly show that there is a common principle controlling the expression of these ten genes. Indeed, most of them are expressed in both retina and optic tectum. All the non-ubiquitously expressed Rev-erb genes also show expression in the pineal, where ROR $\gamma$ $\mathrm{A}$ is expressed at this stage. These data suggest that Rev-erb and ROR genes may be implicated in common signaling pathways acting during development of organs receiving and integrating light input in zebrafish.

\section{Acknowledgements}

We thank Christine and Bernard Thisse for providing the zebrafish genomic DNA library and for zebrafish training of TK. We thank Laure Bernard for very efficient work in the zebrafish facility and Thomas Lamonerie, François Bonneton, and Michael Schubert for critical reading of the manuscript. We are grateful to Association pour la Recherche contre le Cancer, Fondation pour la Recherche Médicale, Centre National de la Recherche Scientifique, Ministere de l'Education Nationale, de la Recherche et de la Technologie and Region Rhone-Alpes for financial support. The authors declare that there is no conflict of interest that would prejudice the impartiality of this scientific work.

\section{References}

Adelmant G, Begue A, Stehelin D \& Laudet V 1996 A functional Reverb alpha responsive element located in the human Rev-erb alpha promoter mediates a repressing activity. PNAS 93 3553-3558.

Akashi M \& Takumi T 2005 The orphan nuclear receptor RORalpha regulates circadian transcription of the mammalian core-clock Bmall. Nature Structural and Molecular Biology 12 441-448.

Balsalobre A, Damiola F \& Schibler U 1998 A serum shock induces circadian gene expression in mammalian tissue culture cells. Cell 93 929-937.

Becker-Andre M, Andre E \& DeLamarter JF 1993 Identification of nuclear receptor mRNAs by RT-PCR amplification of conserved zinc-finger motif sequences. Biochemical and Biophysical Research Communications 194 1371-1379.

Bertrand S, Brunet FG, Escriva H, Parmentier G, Laudet V \& Robinson-Rechavi M 2004 Evolutionary genomics of nuclear receptors: from twenty-five ancestral genes to derived endocrine systems. Molecular Biology and Evolution 21 1923-1937.

Bonnelye E, Vanacker JM, Desbiens X, Begue A, Stehelin D \& Laudet V 1994 Rev-erb beta, a new member of the nuclear receptor superfamily, is expressed in the nervous system during chicken development. Cell Growth and Differentiation 5 1357-1365.
Canaple L, Rambaud J, Dkhissi-Benyahya O, Rayet B, Tan NS, Michalik L, Delaunay F, Wahli W \& Laudet V 2006 Reciprocal regulation of brain and muscle Arnt-like protein 1 and peroxisome proliferatoractivated receptor alpha defines a novel positive feedback loop in the rodent liver circadian clock. Molecular Endocrinology 20 1715-1727.

Chawla A \& Lazar MA 1993 Induction of Rev-ErbA alpha, an orphan receptor encoded on the opposite strand of the alpha-thyroid hormone receptor gene, during adipocyte differentiation. Journal of Biological Chemistry 268 16265-16269.

Chomez P, Neveu I, Mansen A, Kiesler E, Larsson L, Vennstrom B \& Arenas E 2000 Increased cell death and delayed development in the cerebellum of mice lacking the rev-erbA(alpha) orphan receptor. Development 127 1489-1498.

Coste H \& Rodriguez JC 2002 Orphan nuclear hormone receptor Reverbalpha regulates the human apolipoprotein CIII promoter. Journal of Biological Chemistry 277 27120-27129.

Delaunay F, Thisse C, Marchand O, Laudet V \& Thisse B 2000 An inherited functional circadian clock in zebrafish embryos. Science 289 297-300.

Downes M, Carozzi AJ \& Muscat GE 1995 Constitutive expression of the orphan receptor, Rev-erbA alpha, inhibits muscle differentiation and abrogates the expression of the myoD gene family. Molecular Endocrinology 9 1666-1678.

Dumas B, Harding HP, Choi HS, Lehmann KA, Chung M, Lazar MA \& Moore DD 1994 A new orphan member of the nuclear hormone receptor superfamily closely related to Rev-Erb. Molecular Endocrinology 8 996-1005.

Emery P \& Reppert SM 2004 A rhythmic Ror. Neuron 43 443-446.

Forman BM, Chen J, Blumberg B, Kliewer SA, Henshaw R, Ong ES \& Evans RM 1994 Cross-talk among ROR alpha 1 and the Rev-erb family of orphan nuclear receptors. Molecular Endocrinology 8 12531261.

Gamse JT, Shen YC, Thisse C, Thisse B, Raymond PA, Halpern ME \& Liang JO 2002 Otx5 regulates genes that show circadian expression in the zebrafish pineal complex. Nature Genetics 30 117-121.

Gervois P, Chopin-Delannoy S, Fadel A, Dubois G, Kosykh V, Fruchart JC, Najib J, Laudet V \& Staels B 1999 Fibrates increase human REV$\mathrm{ERB} \alpha$ expression in liver via a novel peroxisome proliferatoractivated receptor response element. Molecular Endocrinology 13 400-409.

Gibbs PD \& Schmale MC 2000 GFP as a genetic marker scorable throughout the life cycle of transgenic zebra fish. Marine Biotechnology 2 107-125.

Giguere V, Tini M, Flock G, Ong E, Evans RM \& Otulakowski G 1994 Isoform-specific amino-terminal domains dictate DNA-binding properties of ROR alpha, a novel family of orphan hormone nuclear receptors. Genes and Development 8 538-553.

Guillaumond F, Dardente H, Giguere V \& Cermakian N 2005 Differential control of Bmall circadian transcription by REV-ERB and ROR nuclear receptors. Journal of Biological Rhythms 20 391-403.

Harding HP \& Lazar MA 1993 The orphan receptor Rev-ErbA alpha activates transcription via a novel response element. Molecular and Cellular Biology 13 3113-3121.

Harding HP \& Lazar MA 1995 The monomer-binding orphan receptor Rev-Erb represses transcription as a dimer on a novel direct repeat. Molecular and Cellular Biology 15 4791-4802.

Jaillon O, Aury JM, Brunet F, Petit JL, Stange-Thomann N, Mauceli E, Bouneau L, Fischer C, Ozouf-Costaz C, Bernot A et al. 2004 Genome duplication in the teleost fish Tetraodon nigroviridis reveals the early vertebrate proto-karyotype. Nature 431 946-957.

Laitinen S, Fontaine C, Fruchart JC \& Staels B 2005 The role of the orphan nuclear receptor Rev-Erb alpha in adipocyte differentiation and function. Biochimie 87 21-25.

Laudet V 1997 Evolution of the nuclear receptor superfamily: early diversification from an ancestral orphan receptor. Journal of Molecular Endocrinology 19 207-226. 
Lazar MA, Hodin RA, Darling DS \& Chin WW 1989 A novel member of the thyroid/steroid hormone receptor family is encoded by the opposite strand of the rat c-erbA alpha transcriptional unit. Molecular and Cellular Biology 9 1128-1136.

Miyajima N, Horiuchi R, Shibuya Y, Fukushige S, Matsubara K, Toyoshima K \& Yamamoto T 1989 Two erbA homologs encoding proteins with different T3 binding capacities are transcribed from opposite DNA strands of the same genetic locus. Cell 57 31-39.

Nasevicius A \& Ekker SC 2000 Effective targeted gene 'knockdown' in zebrafish. Nature Genetics 26 216-220.

Neel H, Gondran P, Weil D \& Dautry F 1995 Regulation of pre-mRNA processing by src. Current Biology 1 413-422.

Pena-de-Ortiz S \& Jamieson GA Jr. 1997 Molecular cloning and brain localization of HZF-2 alpha, a new member of the Rev-erb subfamily of orphan nuclear receptors. Journal of Neurobiology 32 341-358.

Preitner N, Damiola F, Lopez-Molina L, Zakany J, Duboule D, Albrecht U \& Schibler U 2002 The orphan nuclear receptor REV-ERBalpha controls circadian transcription within the positive limb of the mammalian circadian oscillator. Cell 110 251-260.

Raspe E, Mautino G, Duval C, Fontaine C, Duez H, Barbier O, Monte D, Fruchart J, Fruchart JC \& Staels B 2002 Transcriptional regulation of human Rev-erbalpha gene expression by the orphan nuclear receptor retinoic acid-related orphan receptor alpha. Journal of Biological Chemistry 277 49275-49281.

Reinking J, Lam MM, Pardee K, Sampson HM, Liu S, Yang P, Williams S, White W, Lajoie G, Edwards A et al. 2005 The drosophila nuclear receptor e75 contains heme and is gas responsive. Cell 122 195-207.

Retnakaran R, Flock G \& Giguere V 1994 Identification of RVR, a novel orphan nuclear receptor that acts as a negative transcriptional regulator. Molecular Endocrinology 8 1234-1244.
Thisse B, Heyer V, Lux A, Alunni V, Degrave A, Seiliez I, Kirchner J, Parkhill JP \& Thisse C 2004 Spatial and temporal expression of the zebrafish genome by large-scale in situ hybridization screening. Methods in Cell Biology 77 505-519.

Torra IP, Tsibulsky V, Delaunay F, Saladin R, Laudet V, Fruchart JC, Kosykh V \& Staels B 2000 Circadian and glucocorticoid regulation of Rev-erbalpha expression in liver. Endocrinology 141 3799-3806.

Triqueneaux G, Thenot S, Kakizawa T, Antoch MP, Safi R, Takahashi JS, Delaunay F \& Laudet V 2004 The orphan receptor Rev-erbalpha gene is a target of the circadian clock pacemaker. Journal of Molecular Endocrinology 33 585-608.

Vu-Dac N, Chopin-Delannoy S, Gervois P, Bonnelye E, Martin G, Fruchart JC, Laudet V \& Staels B 1998 The nuclear receptors peroxisome proliferator-activated receptor alpha and Rev-erbalpha mediate the species-specific regulation of apolipoprotein A-I expression by fibrates. Journal of Biological Chemistry 273 2571325720.

Yin L \& Lazar MA 2005 The orphan nuclear receptor Rev-erbalpha recruits the $\mathrm{N}-\mathrm{CoR} /$ histone deacetylase 3 corepressor to regulate the circadian Bmall gene. Molecular Endocrinology 19 1452-1459.

Yin L, Wang J, Klein PS \& Lazar MA 2006 Nuclear receptor Reverbalpha is a critical lithium-sensitive component of the circadian clock. Science 311 1002-1005.

Received in final form 8 March 2007

Accepted 12 March 2007

Made available online as an Accepted Preprint 13 March 2007 